\title{
Parameter optimization of double side wall method for soft surrounding rock tunnel
}

\author{
Zhihua Yang ${ }^{1}$, Rumiao $\mathrm{He}^{1}, \mathrm{Ke} \mathrm{Li}^{2 *}$ and Hongyan $\mathrm{Guo}^{2}$ \\ ${ }^{1}$ Shidian Baoshi Expressway Investment and Development Co., Ltd, Baoshan, 678000, China \\ ${ }^{2}$ China Merchants Chongqing Communications Technology Research \& Design Institute Co., Ltd, Chongqing, 400000, China
}

\begin{abstract}
When the Xiaojiazhai tunnel is constructed by the double-wall method, different curvature radii have different effects on controlling the stability of the surrounding rock and speeding up the construction progress. By numerically simulating the tunnel excavation under different radius of curvature, it is concluded that $\mathrm{R}$ is adopted respectively. The deformation displacement of surrounding rock is $=11.6 \mathrm{~m} \angle$ 520 and $\mathrm{R}=5.76 \mathrm{~m} \angle 1060$. The maximum horizontal displacement and vertical displacement are smaller when $\mathrm{R}=5.76 \mathrm{~m} \angle 1060$ is selected. According to the analysis results, when $\mathrm{R}=5.76 \mathrm{~m} \angle 1060$ is selected, the deformation of surrounding rock can be controlled to ensure the safety of construction and provide reference for future construction.
\end{abstract}

\section{Introduction}

Due to multiple excavation during double-side wall construction, the surrounding rock has been disturbed many times, which has aggravated the deformation of surrounding rock. The optimization of supporting parameters during construction is of great significance for controlling the deformation of surrounding rock. Therefore, optimizing the double-side wall support parameters is of great significance for speeding up the construction schedule and ensuring construction safety [1-3].

Domestic and foreign scholars have used the theory and numerical simulation to do the following research on the influence of tunnel excavation on the buildings above the tunnel: Deng Wei used numerical simulation to analyze the dynamic construction process of Baise Dakang Tunnel in Guangxi, and obtained the deformation and stress law of surrounding rock in different construction steps [4]. Luo Yong analyzed the construction method and main technical measures when the double-side wall method was used to break the biased surrounding rock in the Qinling Mountains. [5].

Based on the Xiaojiazhai tunnel as an engineering example, this paper analyzes the parameters of different curvature radius when using double-side wall method by numerical simulation method. By comparing the two different supporting parameters, it is concluded that $\mathrm{R}=5.76 \mathrm{~m} \angle 106$ is adopted. It can reduce the deformation of surrounding rock and provide research support for construction safety and control of surrounding rock deformation [6-9].

\section{General situation of Engineering}

The starting distance of the Xiaojiazhai tunnel is $\mathrm{K} 28+228 \sim \mathrm{K} 29+435$, the length is $1207 \mathrm{~m}$, the depth is $110.76 \mathrm{~m}$, the left hole is ZK28+220 ZK29+455, the length is $1235 \mathrm{~m}$, the short tunnel is buried at $104.5 \mathrm{~m}$. The tunnel has a clear distance of $21 \sim 28 \mathrm{~m}$ and the cross section is a separate tunnel. The elevation of the tunnel area is $1569 \sim 1695 \mathrm{~m}$, and the relative height difference is $126 \mathrm{~m}$. It belongs to the dissolution and erosion low mountain landscape. The terrain is steep. The tunnel entrance has rural cement road access, convenient transportation, only the country road in the exit section, the traffic is inconvenient, the vegetation is less. development. 


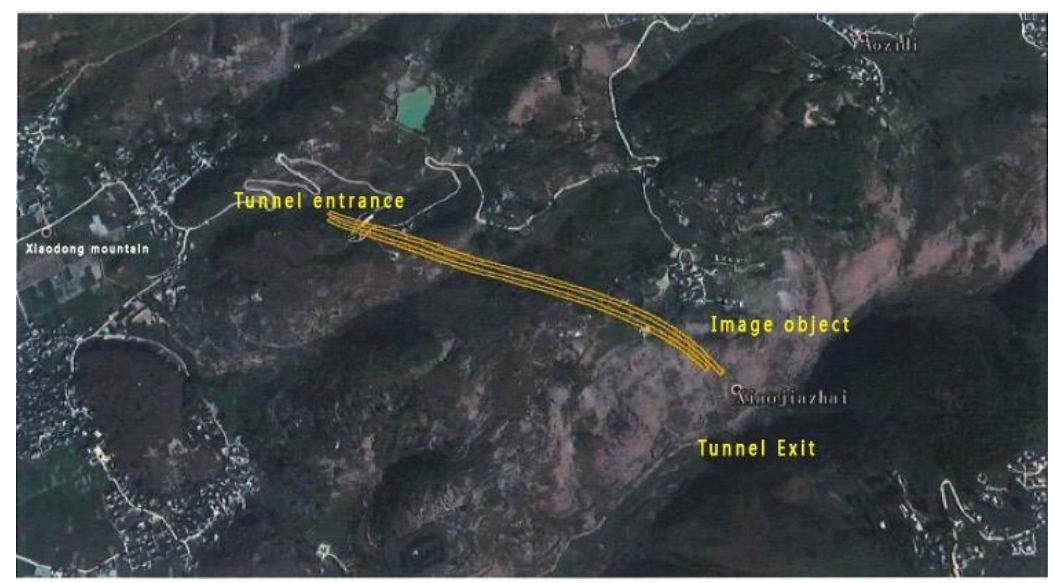

Figure 1 Topography of Xiaojiazhai Tunnel

\subsection{Engineering geological conditions.}

According to the regional geological data of Yunnan Province, the area where the line is located is located in the composite part of the Yunnan-type mountain front structure and the middle branch of the eastern branch of the Qinghai-Tibet-Burma-type structure system. The geological structure is complex in the area, and the tectonic geological structure is the backbone structure. The long-term activity of the zonal structure, the meridional structure is a prominent structural system in the area, which belongs to the meridional tectonic system of the Sichuan-Yunnan system, mainly consisting of the compressive, torsional fracture and small amount of the same direction of the meridional tectonic system.

The stratum of the tunnel crossing area is dominated by the Silurian system of the Silurian system, the Shangrenheqiao Formation (S2r) and the Devonian system (D1) limestone. It belongs to the dissolution and erosion low-mountain landform. From the structure, the tunnel mountain is a single oblique mountain; The shape is regarded as a dome mountain, and the sides of the hole are flat slopes, which is favorable for the drainage of the hole and the stability of the slope, and the mountain shape is full and full. The slope of the entrance section is

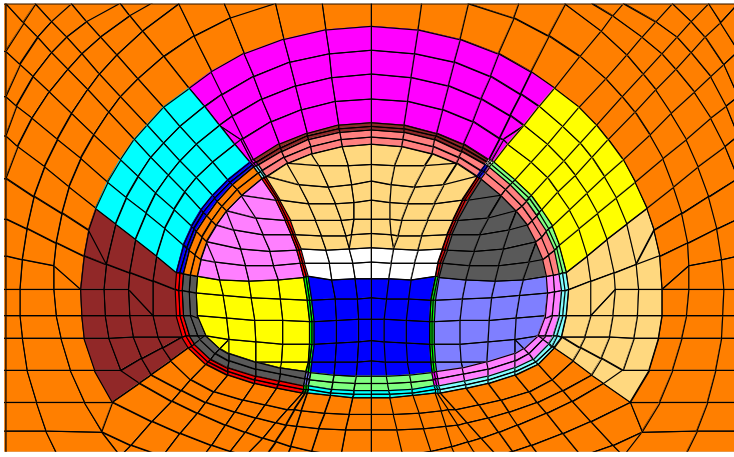

a) $\mathrm{R}=11.6 \mathrm{~m} \angle 52^{0}$ gentle, the natural slope is $15 \sim 25^{\circ}$; the exit section is steep, the natural slope is $25 \sim 45^{\circ}$, and the terrain is undulating.

\subsection{Hydrogeology}

The project area is located in the Nujiang River system, in the Shidian River Basin. The Shidian River originates from the Nangao Mountain Area of the basin and flows through the basin from the south to the north.

\section{Numerical simulation analysis}

\subsection{Parameter selection}

In this thesis, the Midas GTS is used to numerically simulate the two different curvature radius conditions of the double sidewall method, as shown in Figure 2. which are $\mathrm{R}=11.6 \mathrm{~m} \angle 520$, (2) $\mathrm{R}=5.76 \mathrm{~m} \angle 1060$, and the surrounding rock is adopted. The Mohr-Coulomb constitutive model uses an elastic constitutive model for the support and a plane strain model for the second lining.

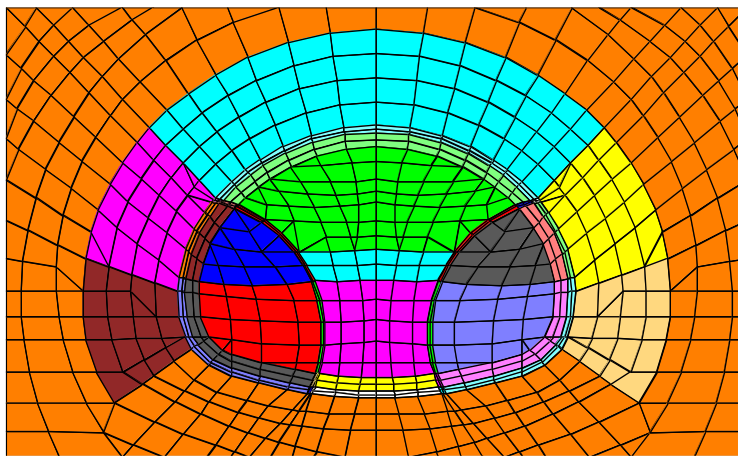

b) $\mathrm{R}=5.76 \mathrm{~m} \angle 106^{0}$

Figure 2. Curvature radius calculation model diagram 
The surrounding rock and support parameters are shown in Table 1.

Table 1. Mechanical parameters of surrounding rock and support

\begin{tabular}{cccccc}
\hline Rock and soil & $\begin{array}{c}\text { Density } \\
(\mathrm{g} / \mathrm{cm} 3)\end{array}$ & $\begin{array}{c}\text { Bearing capacity of foundation } \\
(\mathrm{kPa})\end{array}$ & friction & $\varphi\left({ }_{\circ}\right)$ & $\begin{array}{c}\text { Cohesion } \\
(\mathrm{MPa})\end{array}$ \\
\hline Silty clay & 18.5 & 240 & 12 & 0.03 \\
\hline
\end{tabular}

\subsection{Parameter selection}

The whole process of construction is carried out under the condition that the surrounding rock depth is $20 \mathrm{~m}$. The excavation and support sequence are: 1 step excavation and support on the left guide pit $\rightarrow 2$ left guide pit under the step excavation and support, left guide Pit initial support closure $\rightarrow 3$ right guide pit on the step excavation and support $\rightarrow 4$ right guide pit under the step excavation and support, the right guide pit initial support closure $\rightarrow 5$ middle guide pit on the step excavation and support $\rightarrow 6$ The lower step of the guiding pit is excavated and supported, and the whole ring is initially supported and closed $\rightarrow 7$ Demolition temporary support.

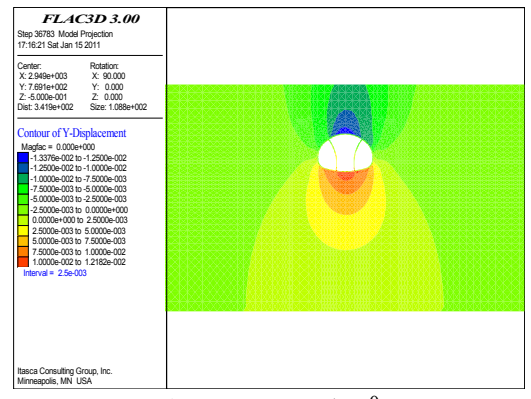

a) $\mathrm{R}=11.6 \mathrm{~m} \angle 52^{0}$

\subsection{Analysis of results}

During the tunnel excavation process, the vertical displacement of the surrounding rock is simulated as shown by different curvature radii. When the radius $\mathrm{R}=11.6 \mathrm{~m}$, the maximum settlement of the vault is $13.4 \mathrm{~mm}$, and the maximum settlement of the vault is $15.7 \mathrm{~mm}$ when $\mathrm{R}=5.76 \mathrm{~mm}$, mainly the excavation of the right guide hole and the excavation of the middle guide hole, re-disturbing the surrounding rock and accelerating the vault. settlement. Although the latter has larger sedimentation than the former, the left and right cave vault settlements are smaller than the former, so the latter scheme is optimal.

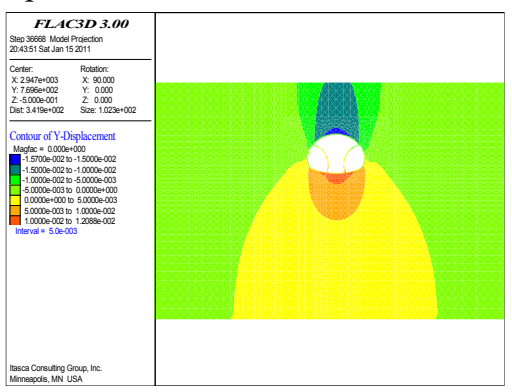

b) $\mathrm{R}=5.76 \mathrm{~m} \angle 106^{0}$

Figure 3. Vertical displacement

During the tunnel excavation process, the horizontal displacement of the surrounding rock is as shown in the different radius of curvature. When the radius $\mathrm{R}=11.6 \mathrm{~m}$, the maximum horizontal displacement of the side wall is

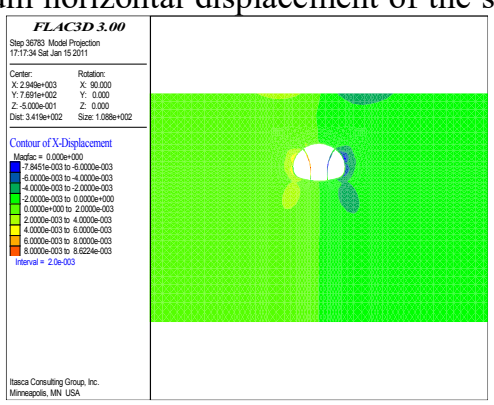

a) $\mathrm{R}=11.6 \mathrm{~m} \angle 52^{0}$
$7.8 \mathrm{~mm}$, and when the radius $\mathrm{R}=5.76 \mathrm{~m}$, the maximum horizontal displacement is $6.9 \mathrm{~mm}$. The latter's horizontal displacement is smaller than the former.

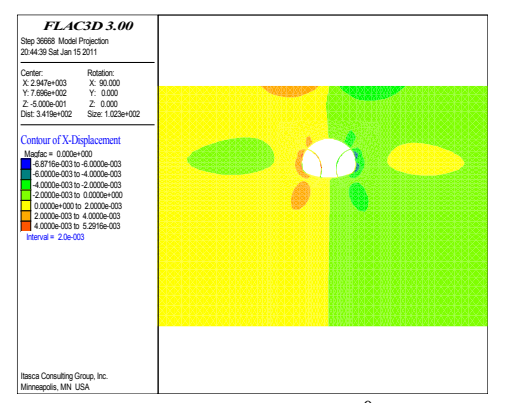

b) $\mathrm{R}=5.76 \mathrm{~m} \angle 106^{0}$

Figure 4. Surrounding rock horizontal displacement

In summary, when using the double-wall method, $\mathrm{R}=5.76 \mathrm{~m} \angle 106$ should be selected, which can better control the deformation.

\section{Conclusion}

Through the comprehensive analysis of Xiaojiazhai tunnel, the influence of different radius of curvature on surrounding rock excavation is studied. Through the numerical simulation of the excavation section, the following conclusions are drawn:

(1) The Xiaojiazhai tunnel should use the curvature form of $\mathrm{R}=5.76 \mathrm{~m} \angle 1060$ to prevent excessive deformation of surrounding rock and strengthen monitoring and measurement.

(2) The tunnel entrance and exit sections are shallowly buried, and the support design is strengthened to prevent construction problems such as roof collapse. 
(3) When the water volume in the tunnel is large, it is recommended to use advanced pre-grouting to strengthen and strengthen the drainage measures inside the cave.

\section{Acknowledgments}

The authors would like to express their appreciation to the National Natural Science Foundation of China (41601574), the Chongqing Basic and Frontier Research Project (cstc2015jcyjBX0118), the Chongqing Science and Technology Innovation Leading Talent Support Program (CSTCCXLJRC201715), and the Chongqing Social Undertakings and Livelihood Security Science and Technology Innovation and Special Program (cstc2017shmsA30010) for providing funding for this research.

\section{Reference}

1. Wang Z.J., Wu F., Wang L., Wang R.L., Gao J.Y. (2019) Study on construction method and surrounding rock deformation characteristics of deep-buried aeolian sand tunnel [J/OL]. Railway standard design: 1-7.

2. Mao J.L. (2019) Research on Design and Construction Technology of Large-span New Loess Highway Tunnel Support[J]. Modern Transportation Technology, 16(01): 61-66.

3. Ma D. (2018) Research on Construction Scheme Optimization of Three-line Station Tunnel under Complex Geological Conditions[J]. Tunnel Construction (Chinese and English),38(S2): 253-260.

4. Song Z.P., Zhang Q., Zhao K.M., Zhang X.G., Zhang X.W., Wang J.J. (2018) Study on the advance construction optimization of tunnel double-conducting tunnel based on on-site monitoring and numerical analysis[J]. Journal of Xi'an University of Architecture \& Technology(Natural Science Edition),0( 05): 654-661.

5. Zhao N., Wang J.H., Zhang J.X. (2018) Selection and optimization of excavation method for large-span flat single-hole four-lane highway tunnel[J]. Journal of Highway and Transportation Technology, 34(S1): 177-182.

6. Wang D.Y., Yuan J.X., Wang J.P., Cheng Y., Wang K., Xia Y., Wang H.Q. (2018) Study on rapid tunneling method and stability control technology for shallow buried soft surrounding rock tunnel[J]. Modern Tunnel Technology, 55(04): 178-185.

7. Wang R.J., Liu Z.Q., Yang J.C. (2018) Optimization of construction method for large-span tunnel of squeezed surrounding $\operatorname{rock}[\mathrm{J}]$. Railway Construction, 58(05): 62-65.

8. Deng W., Shi X.F., Yang G.L., Zhang H.Q. (2018) Numerical Modeling and Mechanical Analysis of Double Side Wall Guide Method for Large
Cross-section Tunnels[J]. Highway, 63(03):253-259.

9. Luo Y. (2018) Application of two side wall guide pit excavation method in construction of broken-biased surrounding rock tunnel[ $\mathrm{J}]$. Chinese and Foreign Architecture, (02): 150-152.

10. Zheng J. (2018) Key Construction Technology of Shield Tunneling in Railway Station Area[J]. Journal of Shijiazhuang Railway University (Natural Science Edition),31(03): 29-35. 